http://dx.doi.org/10.1590/0104-1428.1355

\title{
Filmes Compostos Biodegradáveis a Base de Amido de Mandioca e Proteína de Soja
}

\author{
Geisa Oliveira Rocha, Mônica Guimarães Farias \\ Programa de Pós-Graduação em Ciência e Tecnologia de Alimentos, Universidade Federal Rural do \\ Rio de Janeiro - UFRRJ

\section{Carlos Wanderlei Piler de Carvalho, José Luis Ramírez Ascheri, Melicia Cintia Galdeano Embrapa Agroindústria de Alimentos, CTAA/Embrapa, Rio de Janeiro, $R J$}

\begin{abstract}
Resumo: Filmes provenientes de biopolímeros (polissacarídeos e proteínas) apresentam-se como alternativa ao uso de derivados petroquímicos, possibilitando a formação de matrizes contínuas, e a otimização de parâmetros como pH e tipo de plastificante pode resultar em materiais com propriedades melhoradas. Neste estudo, filmes de amido de mandioca produzidos por casting foram avaliados quanto a adição de extrato proteico de soja (EPS), glicerol e pH do meio. O aumento da concentração de EPS levou ao escurecimento dos filmes, ao aumento da solubilidade e aumentou o pH. O maior teor de plastificante e o menor $\mathrm{pH}$ elevaram a permeabilidade ao vapor de água (PVA). A menor PVA ( 0,057 $\mathrm{g} \mathrm{mm} \mathrm{h} \mathrm{m}^{-1} \mathrm{mPa}^{-1}$ ) foi obtida com máximo teor de EPS (47\%) e 13\% de glicerol em pH 12 . A força de perfuração variou de 0,08 a $2,78 \mathrm{~N}$, sendo os maiores valores com adição de EPS e glicerol em nível intermediário $(30 \%) \mathrm{em} \mathrm{pH}$ neutro. A maior deformação na perfuração (31,9\%) ocorreu no teor de EPS mais baixo (13\%) e de glicerol mais alto (47\%). Considerando-se os fatores desejáveis: baixa PVA, baixa solubilidade e boa resistência mecânica, os filmes produzidos com 15,2\% de EPS, 29,2\% de glicerol em pH 6,1 foram os que mais bem atenderam a estas características.
\end{abstract}

Palavras-chave: glicerol, $\mathrm{pH}$, perfuração, permeabilidade ao vapor de água.

\section{Biodegradable Composite Films Based on Cassava Starch and Soy Protein}

\begin{abstract}
Films from biopolymers (polysaccharides, proteins) are an alternative to the use of petrochemical derivatives, with possible formation of continuous matrices. Upon optimizing parameters such as $\mathrm{pH}$ and type of plasticizer, one may obtain materials with improved properties. In this study, cassava starch films produced by casting were evaluated concerning soybean protein extract (SPE) content, glycerol and varied $\mathrm{pH}$ conditions. Upon increasing the concentration of SPE, the films became darker, more soluble and the $\mathrm{pH}$ increased. The higher plasticizer content and the lower $\mathrm{pH}$ increased the water vapor permeability (WVP). The lowest WVP $\left(0.057 \mathrm{~mm} \mathrm{~g}^{-1} \mathrm{~h}-\mathrm{m} 2 \mathrm{kPa}^{-1}\right)$ was obtained at the maximum content of SPE (47\%) and 13\% glycerol at $\mathrm{pH} 12$. The puncture force ranged from 0.08 to $2.78 \mathrm{~N}$ and the highest values were obtained with intermediate level of SPE and glycerol $(30 \%)$ at neutral $\mathrm{pH}$. The highest puncture deformation value (31.9\%) occurred at the lowest SPW content (13\%) and highest glycerol content (47\%). Considering as the desirable factors: low WVP, low solubility and good mechanical strength, one concludes that the films produced from cassava starch with $15.2 \%$ of EPS, $29.2 \%$ of glycerol at $\mathrm{pH} 6.1$ exhibited the best performance.
\end{abstract}

Keywords: glycerol, ph, puncture, water vapor permeability.

\section{Introdução}

O impacto ambiental do uso de materiais sintéticos, na forma de plásticos, tem estimulado o desenvolvimento de embalagens biodegradáveis a partir de fontes naturais renováveis ${ }^{[1]}$, pois devido a relativa inércia e resistência a biodegradação, os polímeros sintéticos, foram requeridos inicialmente. Os polímeros formados por hidrocarbonetos são resistentes ao ataque químico e biológico, assegurando longevidade e outras propriedades mantidas por períodos longos ${ }^{[2,3]}$. No entanto, o descarte destes materiais no meio ambiente, dificultam a degradação da matéria orgânica. Desta forma, o uso de polímeros biodegradáveis mostra-se uma possível solução para os impactos ambientais gerados pelo descarte inadequado dos polímeros convencionais ${ }^{[2]}$.
Entre os polímeros naturais, o amido e a proteína têm sido considerados bastante promissores para elaboração de biofilmes ${ }^{[4]}$. O amido é o biopolímero mais abundante no mundo após a celulose e consiste de moléculas lineares (amilose) e ramificadas (amilopectina) de glicose $\mathrm{e}^{[5]}$. As proteínas possuem uma estrutura com até 20 monômeros diferentes (aminoácidos) de alto potencial para interações intermoleculares. Assim, ambos são amplamente utilizados na produção de biofilmes devido às suas propriedades funcionais, variedade de fontes disponíveis e de baixo custo de produção ${ }^{[6]}$. A formação de filmes de proteína tem sido possível em $\mathrm{pH}$ distante do seu ponto isoelétrico ( $\mathrm{pI}$ ), uma vez que no pI, a coagulação não permite a formação de uma matriz homogênea ${ }^{[7]}$. 
Já foi mostrado que filmes à base de amido ou à base de proteínas apresentam efetiva barreira aos gases $\left(\mathrm{CO}_{2}\right.$ e $\mathrm{O}_{2}$ ), No entanto, a alta permeabilidade ao vapor de água destes materiais em função do caráter hidrofílico dos polímeros, pode limitar sua aplicação na forma de embalagens ${ }^{[8]}$. Segundo Tang et al. ${ }^{[9]}$ uma forma de melhorar as propriedades dos biomateriais é através do desenvolvimento de filmes compostos, uma vez que a combinação dos polímeros tem como vantagem agregar os pontos positivos de cada um dos constituintes isolados.

O Brasil é o segundo produtor mundial de mandioca. A relevância econômica dessa cultura vem crescendo nos últimos anos decorrentes, principalmente, dos processos que procuram agregar valor ao seu beneficiamento ${ }^{[10]}$, como por exemplo, sua utilização na elaboração de produtos biodegradáveis. Por outro lado, a soja é uma fonte proteica vegetal disponível em abundância em território nacional e economicamente competitiva ${ }^{[11]}$, o que também justifica sua utilização em aplicações não alimentares ${ }^{[12]}$.

Como os filmes elaborados por esses polímeros são pouco flexíveis e quebradiços torna-se necessário à adição de plastificante à matriz polimérica para melhorar suas características de flexibilidade. Os plastificantes reduzem as interações entre as moléculas adjacentes, aumentando a flexibilidade do filme ${ }^{[13]}$. Para aplicação de um plastificante é extremamente importante, que este seja adequadamente compatível com o polímero utilizado e a definição da proporcionalidade entre os componentes a fim de adequar a composição final a uma determinada aplicação ${ }^{[14]}$.

Assim, o objetivo deste trabalho foi estudar o efeito da adição de extrato proteico de soja, do teor de glicerol e do $\mathrm{pH}$ do meio nas propriedades de filmes a base de amido de mandioca.

\section{Material e Métodos}

\section{Materiais}

As matérias-primas utilizadas foram extrato proteico de soja (EPS) (ArmaZen Produtos Naturais, RJ, Brasil) e amido de mandioca (Yoki Alimentos, SP, Brasil) adquiridos no comércio local da cidade do Rio de Janeiro.

\section{Produção dos filmes}

Os filmes foram produzidos, segundo a técnica de casting, com fécula de mandioca, extrato proteico de soja (13,18 a 46,82\% de substituição da fécula) e glicerol como plastificante $(13,18$ a 46,82\% de substituição da fécula) em viscoamilógrafo Brabender (Duisburg, Alemanha). As quantidades foram calculadas com base no teor de sólidos totais da mistura $(2,5 \% \mathrm{p} / \mathrm{p})$. O EPS, a fécula e o glicerol foram dissolvidos em água. $\mathrm{O} \mathrm{pH}(1,9$ a 12,0$)$ foi ajustado com a adição de ácido acético glacial e hidróxido de sódio e as soluções filmogênicas foram aquecidas sob agitação até $90{ }^{\circ} \mathrm{C}$, permanecendo nesta temperatura por 10 min e resfriadas a $50{ }^{\circ} \mathrm{C}$. Após resfriamento, $41,7 \mathrm{~g}$ da solução foram vertidas em placas de $142 \mathrm{~mm}$ de diâmetro e o material foi seco em estufa com circulação de ar a $30{ }^{\circ} \mathrm{C}$ por $24 \mathrm{~h}$. Após secagem, os filmes foram removidos das placas e acondicionados em câmaras com umidade relativa (UR) de 52,9\%.
Após 6 dias, os materiais foram caracterizados quanto a espessura, cor, opacidade, solubilidade em água, permeabilidade ao vapor de água e propriedades mecânicas conforme o delineamento utilizado (Tabela 1).

A espessura de cada filme foi determinada em 5 pontos aleatórios usando um micrômetro digital Fowler IP 54 (Newton, EUA), com sensibilidade de $\pm 0,001 \mathrm{~mm}$.

\section{Caracterização dos Filmes}

\section{Cor}

Foi utilizado um colorímetro Suga SM-4-CH (Tókio, Japão) no sistema Hunter com abertura de $30 \mathrm{~mm}$ de diâmetro. Os parâmetros de cor medidos em relação à placa branca $(\mathrm{L}=90,22 ; \mathrm{a}=-2,34 ; \mathrm{b}=1,39)$ foram: $\mathrm{L}=$ luminosidade $(0=$ preto e $100=$ branco $)$, a $(-80$ a zero $=$ verde e zero $\mathrm{a}+100=$ vermelho $), \mathrm{b}(-100$ a zero $=$ azul e zero a $+70=$ amarelo) e $\Delta \mathrm{E}$ (diferença total de cor) $=$ $\sqrt{(\Delta \mathrm{L})^{2}+(\Delta a)^{2}+(\Delta b)^{2}}(\text { Gennadios et al. })^{[15]}$

\section{Opacidade aparente}

Foi determinada em um espectrofotômetro FEMTO (modelo 700 PLUS, São Paulo, Brasil) segundo Shiku et al. ${ }^{[16]}$. Os filmes foram cortados e aderidos à parede interna da cubeta de modo a permanecer posicionado perpendicular ao feixe de luz. Uma cubeta vazia foi usada como referência. Varreu-se a faixa do comprimento de onda da luz visível, a $500 \mathrm{~nm}$ para cada filme e a opacidade foi calculada conforme a equação: Opacidade $=\mathrm{A}_{500} / \mathrm{T}$, onde $\mathrm{A}_{500}$ é a absorção a $500 \mathrm{~nm}$ e T é a espessura do filme em $\mathrm{mm}$.

\section{Solubilidade em água}

Os materiais cortados em formato circular (diâmetro $20 \mathrm{~mm}$ ) foram secos, pesados e submergidos em água destilada $\left(25^{\circ} \mathrm{C}\right)$ sob lenta agitação em banho-maria por $24 \mathrm{~h}$. Após este período, as amostras foram removidas da água e secas em estufa a $105^{\circ} \mathrm{C} / 4 \mathrm{~h}$. A porcentagem de solubilidade foi calculada segundo Gontard et al..$^{[17]}$ através da equação: $\% \mathrm{MS}=(P I-P F / P I) \times 100$, onde $\% \mathrm{MS}$ é a porcentagem de material seco solubilizado; PI é o peso inicial do material seco; PF é o peso final do material seco não solubilizado.

\section{Permeabilidade ao vapor de água}

A permeabilidade ao vapor de água (PVA) foi determinada gravimetricamente a $25{ }^{\circ} \mathrm{C}$, de acordo com o método ASTM E96-80 ${ }^{[18]}$ com modificações. Os filmes

Tabela 1. Variáveis independentes para delineamento central composto no processo de elaboração de biofilme de amido de mandioca e extrato de soja.

\begin{tabular}{lrrccc}
\hline \multirow{2}{*}{ Variáveis Independentes } & \multicolumn{5}{c}{ Níveis } \\
\cline { 2 - 6 } & \multicolumn{1}{c}{$\alpha^{\mathrm{a}}$} & $\mathbf{- 1}$ & $\mathbf{0}$ & $\boldsymbol{+ 1}$ & $+\alpha$ \\
\hline EPSb (\%) & 13,18 & 20 & 30 & 40 & 46,82 \\
Glicerol (\%) & 13,18 & 20 & 30 & 40 & 46,82 \\
$\mathrm{pH}$ & 1,95 & 4 & 7 & 10 & 12,05 \\
\hline
\end{tabular}

${ }^{\mathrm{a}} \alpha=1.682 ;{ }^{\mathrm{b}} \mathrm{EPS}=$ Extrato proteico de soja. 
(40 mm de diâmetro) foram colocados nas células de permeação contendo água destilada. Estas células foram acondicionadas em dessecador contendo sílica gel azul e o conjunto foi armazenado a $25{ }^{\circ} \mathrm{C}$ e UR de $50 \%$ em incubadora BOD (Hydrosan, Belo Horizonte, Brasil). As pesagens foram realizadas em intervalos de $24 \mathrm{~h}$ ao longo de 9 dias. Mudanças na massa da célula de permeação foram graficadas em função do tempo (s) e, da reta obtida por regressão linear, foi determinado o coeficiente angular e calculada a taxa de permeabilidade ao vapor de água (TVA) como TVA $=\mathrm{g} / \mathrm{t} \cdot \mathrm{A}$, onde $\mathrm{g} / \mathrm{t}$ é o coeficiente angular da reta e A é a área de permeação $\left(\mathrm{m}^{2}\right)$. A PVA foi calculada usando a equação $\mathrm{PVA}=(\mathrm{TVA} \cdot x) / \Delta \mathrm{P}$, onde $x$ é a espessura média dos filmes $(\mathrm{mm})$ e $\Delta \mathrm{P}$ é a diferença de pressão de vapor do ambiente contendo sílica $\left(0 \mathrm{kPa}\right.$ a $\left.25^{\circ} \mathrm{C}\right)$ e água pura $\left(3,17 \mathrm{kPa}\right.$ a $\left.25^{\circ} \mathrm{C}\right)$.

\section{Teste de perfuração}

Foram determinadas a força $(\mathrm{N})$ e a deformação (mm) na ruptura utilizando um analisador de textura Texture Analyser TA HDi (Stable Microsystems, Surrey, Inglaterra) segundo Gontard ${ }^{[19]}$. Os corpos de prova (20 $\mathrm{mm}$ de comprimento e $15 \mathrm{~mm}$ de largura) foram fixados no equipamento com plataforma de garras móvel com abertura de $10 \mathrm{~mm}$ de diâmetro e perfurados por um probe com ponta de esfera com $3 \mathrm{~mm}$ de diâmetro a $1 \mathrm{~mm} / \mathrm{s}$. A força de ruptura (F) e o deslocamento (D) na perfuração foram determinados diretamente das curvas de força $v s$ deformação. A deformação na ruptura por perfuração $\left(\Delta 1 / 1_{0}\right)$

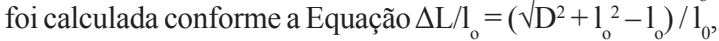
onde $1_{0}$ é o comprimento inicial do filme, igual a metade da abertura da célula de medida $(5 \mathrm{~mm})^{[17]}$.

\section{Delineamento experimental}

Foi usado o delineamento central composto rotacional de $2^{\circ}$ ordem, com três variáveis independentes em três níveis de variação, seis repetições no ponto central e seis axiais, totalizando 20 ensaios $^{[20]}$. As variáveis independentes foram teor de extrato proteico de soja $(13,18 ; 20 ; 30 ; 40$ e $46,82 \%)$, glicerol $(13,18 ; 20 ; 30 ; 40$ e 46,82\%) e pH $(1,9 ; 4 ; 7 ; 10$; $12,05)$. As variáveis dependentes foram permeabilidade ao vapor de água, opacidade, cor, solubilidade e perfuração.

$\mathrm{Na}$ otimização do processo de produção dos filmes foram consideradas as seguintes propriedades físicas: permeabilidade ao vapor de água, solubilidade em água e resistência mecânica. A baixa PVA, a baixa solubilidade e a alta resistência mecânica foram as características consideradas desejáveis para a obtenção de um bom filme. Desta forma, foram seguidos alguns critérios, com base nas restrições citadas, para os valores mínimos, intermediários e máximos de cada resposta, com o objetivo encontrar os valores operacionais ótimos das variáveis independentes, que satisfizessem simultaneamente os requisitos necessários às variáveis respostas (função desejabilidade). Os dados experimentais foram analisados usando o Statistica 7.0 (StatSoft, Tulsa, EUA).

\section{Resultados e Discussão}

Os filmes apresentaram espessura entre 0,107 e $0,132 \mathrm{~mm}$, com aspecto contínuo e sem fraturas. Os modelos de regressão estão apresentados na Tabela 2 . Os modelos para opacidade e PVA apresentaram baixo coeficiente de determinação $\left(\mathrm{R}^{2}\right)$, explicando somente parte das variações encontradas. Alguns modelos apresentaram falta de ajuste significativa, indicando não representar adequadamente o sistema, mas ainda assim podem ser considerados úteis para análise de tendência ${ }^{[21]}$.

\section{Opacidade}

A opacidade dos filmes variou de 2,16 a 4,88, sendo que quanto maior o valor, mais opaco o filme. Esses valores foram similares aos encontrados por Cao et al. ${ }^{[22]} \mathrm{em}$ filmes de proteína isolada de soja e gelatina. Os tratamentos não diferiram entre si $(\mathrm{p} \geq 0,05)$ mostrando que os teores de EPS e de glicerol, assim como a variação do $\mathrm{pH}$ não afetaram a opacidade dos materiais (Tabela 2). O modelo apresentou

Tabela 2. Coeficientes de regressão e análise de variância (ANOVA) dos modelos matemáticosa das variáveis dependentes.

\begin{tabular}{|c|c|c|c|c|c|c|}
\hline \multirow{2}{*}{ Variáveis } & \multicolumn{6}{|c|}{ Variáveis Dependentes } \\
\hline & Op & $\Delta \mathbf{E}$ & Sol & PVA & $\mathbf{F P}$ & DF \\
\hline EPS & 6,17 & $361,08 * *$ & $34,57^{* *}$ & 4,63 & 3,72 & $1,3 \mathrm{E}+07^{* *}$ \\
\hline $\mathrm{EPS}^{2}$ & 2,04 & 1,79 & $11,96^{*}$ & 4,33 & $18,66^{*}$ & $6,3 \mathrm{E}+06^{* *}$ \\
\hline GLI & 9,03 & 0,52 & 0,82 & $20,87^{*}$ & 5,29 & $2,0 \mathrm{E}+07 * *$ \\
\hline $\mathrm{GLI}^{2}$ & 0,21 & $11,16^{*}$ & $131,63 * *$ & 0,17 & $33,51 * *$ & $7,1 \mathrm{E}+05 * *$ \\
\hline $\mathrm{pH}$ & 1,07 & $9,85^{*}$ & $15,53 *$ & $12,37^{*}$ & 5,08 & $9,9 \mathrm{E}+04 * *$ \\
\hline $\mathrm{pH}^{2}$ & 3,07 & $11,40 *$ & 3,26 & $13,39^{*}$ & $31,32 * *$ & $1,6 \mathrm{E}+07 * *$ \\
\hline EPS x GLI & 0,32 & 0,02 & $10,44^{*}$ & 2,47 & 0,92 & $5,2 \mathrm{E}+06^{* *}$ \\
\hline EPS $\times \mathrm{pH}$ & 0,11 & 0,08 & 0,76 & $16,38^{*}$ & 1,71 & $6,9 \mathrm{E}+05 * *$ \\
\hline GLI x pH & 0,37 & 0,39 & 1,53 & 4,14 & 3,83 & $5,7 \mathrm{E}+06^{* *}$ \\
\hline $\mathrm{R}^{2}$ & 0,66 & 0,73 & 0,77 & 0,62 & 0,80 & 0,92 \\
\hline Falta de ajuste & 1,87 & $29,27^{*}$ & $11,22^{*}$ & $9,70^{*}$ & 3,28 & $1,2 \mathrm{E}+06^{* *}$ \\
\hline
\end{tabular}

amodelo completo: $Y=\left(b_{0}+b_{1} X_{1}+b_{2} X_{2}+b_{3} X_{3}+b_{11} X_{1}^{2}+b_{22} X_{2}^{2}+b_{33} X_{2}^{3}+b_{12} X_{1} X_{2}+b_{13} X_{1} X_{3}+b_{23} X_{2} X_{3}+\varepsilon\right.$, EPS $=$ extrato proteico de soja; $\mathrm{GLI}=$ glicerol; $\mathrm{pH}=$ potencial hidrogeniônico; $\mathrm{Op}=$ opacidade; $\Delta \mathrm{E}=$ cor; Sol = solubilidade em água $(\%)$; PVA $=$ permeabilidade ao vapor de água $\left(\mathrm{g} \cdot \mathrm{mm} \cdot \mathrm{h}^{-1} \cdot \mathrm{m}^{2} \mathrm{kPa}^{-1}\right) ; \mathrm{FP}=$ força de perfuração na ruptura $(\mathrm{N}) ; \mathrm{DF}=$ deformação na ruptura $(\%) ;{ }^{*}$ significativo em nível de $\mathrm{p} \leq 0,05$; $* *$ significativo em nível de $\mathrm{p} \leq 0,01$. 
baixo coeficiente de determinação $\left(\mathrm{R}^{2}\right)$ explicando apenas $66 \%$ das variações encontradas.

\section{Cor}

A cor dos filmes pode afetar sua aceitação tanto em aplicações comestíveis como não comestíveis (embalagens). A diferença de cor $(\Delta \mathrm{E})$ dos filmes de amido de mandioca adicionados de EPS variou de 8,14 a 17,26. A ANOVA (Tabela 2) mostrou que o maior efeito na cor dos filmes $(p \leq 0,05)$ foi exercido pela adição de EPS. A diferença de cor aumentou com a adição do EPS na matriz polimérica (Figura 1a e 2b), o que pode ser explicada pela cor amarelada característica da matéria-prima. Este fato também foi observado por Sobral et al. ${ }^{[23]} \mathrm{em}$ filmes de proteínas miofibrilares e sarcoplasmáticas de tilápia-donilo, verificando maior coloração desses filmes com adição de maior teor de proteínas. Os materiais do presente trabalho

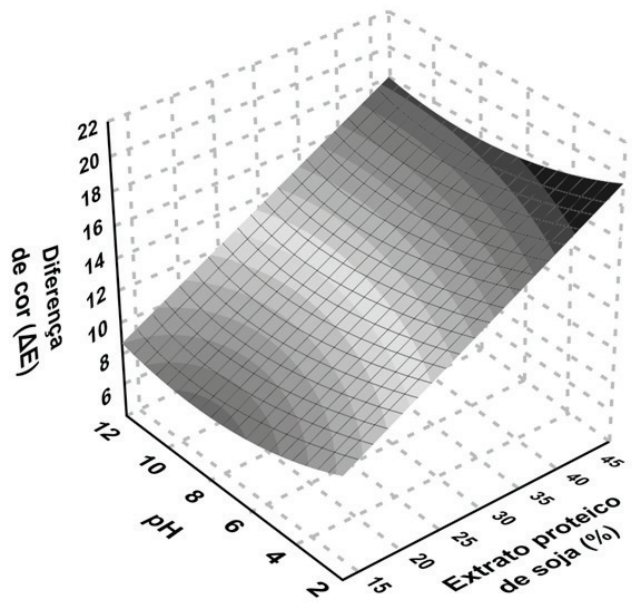

(a) apresentaram coloração mais acentuada do que os filmes elaborados com proteína miofibrilar de tilápia-do-nilo $(\Delta \mathrm{E}$ entre 7,0 e 8,0$)^{[24]}$.

\section{Solubilidade em água}

A solubilidade (Tabela 2) foi influenciada pelos efeitos lineares do EPS e do $\mathrm{pH}$, quadráticos do EPS e do glicerol e pela interação EPS e glicerol, variando de 14,8 a 61,0\%. O aumento do teor de proteína, o qual levou ao aumento da solubilidade dos filmes (Figura 2), também foi observado por Fakhoury et al. ${ }^{[25]}$ em filmes de amido de mandioca adicionados de gelatina. Segundo os autores, quando a proteína é adicionada à matriz amilácea, esta se instala entre as cadeias de amilose e amilopectina levando à redução das interações, assim ocorre as cadeias, aumento do volume livre e permitindo maior difusão da água. Estes autores ainda acrescentam que o aumento dos grupos hidrofílicos

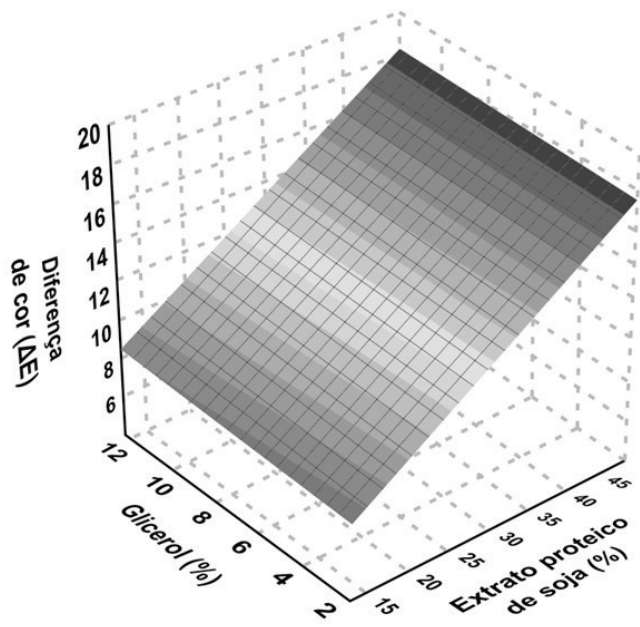

(b)

Figura 1. Efeito do teor de extrato proteico de soja (\%), glicerol (\%) e do $\mathrm{pH}$ na diferença de cor $(\Delta \mathrm{E})$ dos filmes de amido de mandioca. (a) glicerol $30 \%$ e (b) $\mathrm{pH} 7,0$.

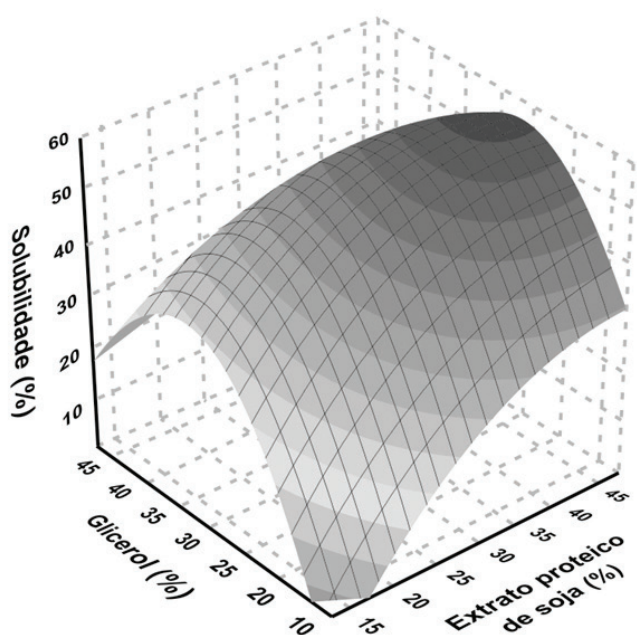

(a)

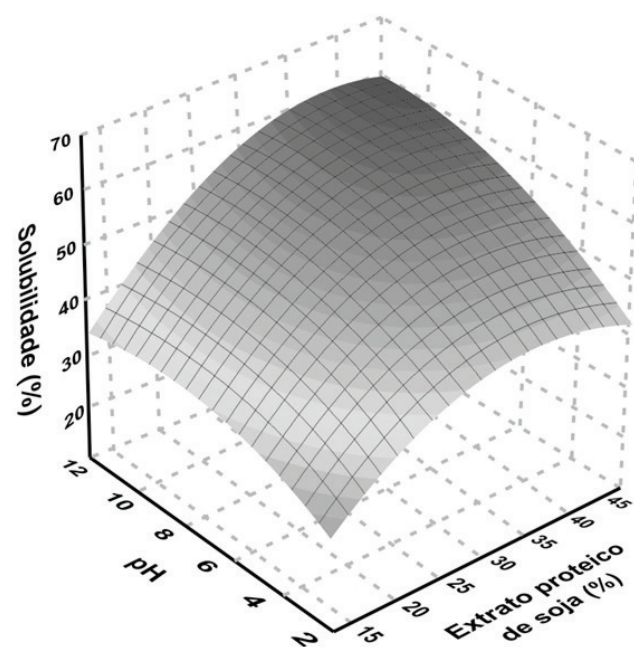

(b)

Figura 2. Efeito dos teores de extrato proteico de soja, glicerol e pH na solubilidade dos filmes de amido de mandioca. (a) $\mathrm{pH} 7,0 \mathrm{e}$ (b) glicerol $30 \%$. 
na massa final da amostra também podem ser responsáveis por aumentar a solubilidade. Além disso, como relatado no trabalho de Rhim e Lee ${ }^{[26]}$, as proteínas de soja apresentam cerca de $58 \%$ de aminoácidos polares, o que resulta em alta polaridade resultando no aumento da afinidade por água com consequente aumento da solubilidade dos filmes.

É interessante notar que no processo de obtenção do filme a $90^{\circ} \mathrm{C}$ em excesso de água e cisalhamento, os quais são necessários para o rompimento total da região cristalina do amido (amilopectina) levando o colapso da organização estrutural do grânulo, ocorra agregação das proteínas do EPS. No entanto, é possível que a agregação das proteínas nesta mistura seja reduzida pela interação com amilose e amilopectina estendidas ${ }^{[27]}$. Com isso, as proteínas manteriam o seu caráter hidrofílico mesmo após formado o filme pela perda de água livre, já que estariam combinadas com as moléculas de amido (amilose e amilopectina).

$\mathrm{O}$ aumento no valor do $\mathrm{pH}$ da solução filmogênica também favoreceu a solubilidade, possivelmente devido ao distanciamento do $\mathrm{pI}$ da proteína de soja ( $\mathrm{pH} 4,5)$, onde a solubilidade é mínima. Bourtoom et al. ${ }^{[28]}$ também observaram que filmes de proteína de peixe apresentaram solubilidade mais alta em pH maior que 10 . Com relação ao efeito do $\mathrm{pH}$ em proteínas de soja no uso em filmes, Jiang et al. ${ }^{[29]}$ afirmaram que o preaquecimento antes da formação do filme tem notável influencia na solubilidade das proteínas de soja e concluíram que há uma inversa correlação entre a temperatura e a lixiviação da proteína em filmes tratados com alteração, exceto no ponto isoelétrico da proteína.

O efeito da interação EPS e plastificante resultou em aumento da solubilidade em alta concentração de proteína e valores médios de glicerol (Tabela 2). A redução na solubilidade observada em alto teor de glicerol pode ser devida à interação aumentada entre plastificante e proteína e/ou carboidrato, deixando menos sítios para interação com a água.

\section{Permeabilidade ao Vapor de Água (PVA)}

A PVA dos filmes foi influenciada pelo glicerol, $\mathrm{pH}$ e interação EPS e pH (Tabela 2). Quanto maior o teor de glicerol, maior foi a PVA (Figura 3). Segundo Cuq et al. ${ }^{[30]}$, com a adição de glicerol, a rede polimérica torna-se menos densa e, consequentemente, mais permeável.

A PVA aumentou com a redução do $\mathrm{pH}$. Segundo BeMiller \& Whistler ${ }^{[31]}$ em $\mathrm{pH}$ ácido pode ocorrer hidrólise das ligações glicosídicas/peptídicas resultando em fragmentos menores, o que poderia criar espaços vazios na rede do filme, explicando o aumento na PVA.

A interação EPS e pH mostrou que a combinação de $\mathrm{pH}$ alcalino com os menores teores de extrato favoreceu a redução da PVA, possivelmente devido ao distanciamento do $\mathrm{pI}$ da proteína e, sendo assim, permitiu que mais interações intercadeias (amido-proteína) fossem estabelecidas, reduzindo a taxa de difusão de água dentro do filme ${ }^{[32]}$.

A máxima PVA foi de $0,393 \mathrm{~g} \mathrm{~mm} \mathrm{~h}^{-1} \mathrm{~m}^{-2} \mathrm{kPa}^{-1}$ para os filmes elaborados com o máximo teor de EPS (47\%) e de glicerol (47\%) em pH 4,0. A menor PVA foi de $0,057 \mathrm{~g} \mathrm{~mm} \mathrm{~h}^{-1} \mathrm{~m}^{-2} \mathrm{kPa}^{-1}$ obtida com $47 \%$ de EPS e $13 \%$ de glicerol em $\mathrm{pH} 12,0$.

\section{Força na perfuração}

A força de ruptura na perfuração foi influenciada apenas pelos efeitos quadráticos do plastificante, do EPS e do $\mathrm{pH}$ (Tabela 2), variando de 0,08 a 2,78 N. Os maiores valores foram obtidos em nível intermediário de adição de EPS e glicerol $(30 \%)$ em pH neutro $(7,0)$.

A força de perfuração primeiro aumentou e depois declinou com o aumento da adição de proteína (Figura 4).

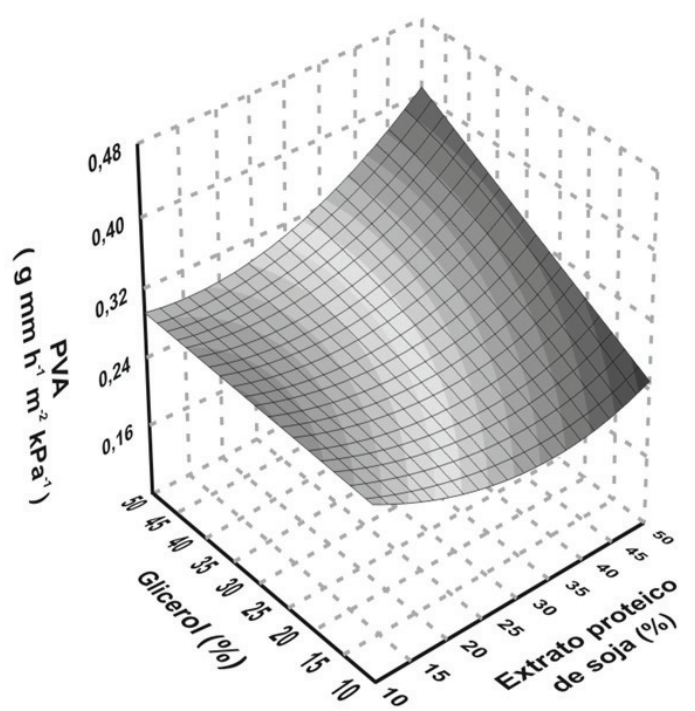

(a)

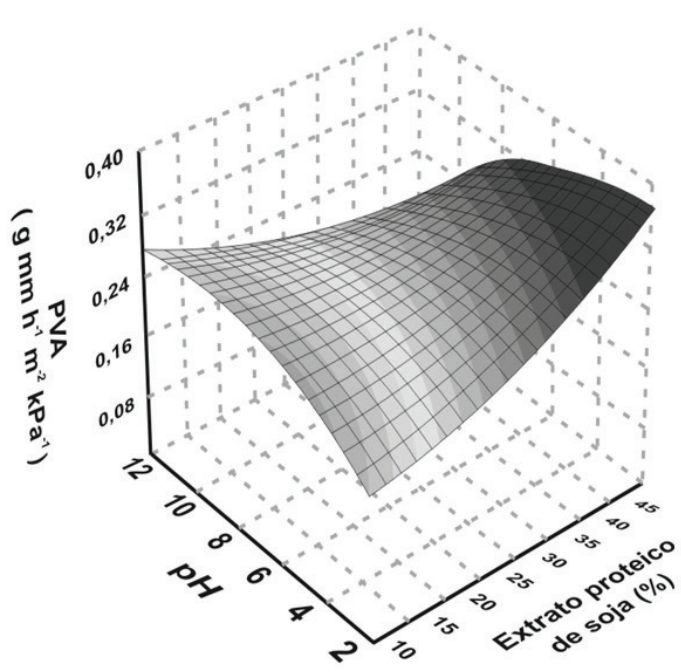

(b)

Figura 3. Efeito dos teores de glicerol, extrato proteico de soja e do $\mathrm{pH}$ na permeabilidade ao vapor de água (PVA) dos filmes de amido de mandioca. (a) $\mathrm{pH} 7,0$ e (b) glicerol $30 \%$. 
Isto porque ocorre um aumento no teor de matéria-seca resultando em um número maior de cadeias responsáveis por aumentar as interações intermoleculares. No entanto com a continuidade do aumento do teor proteico pode ter ocorrido uma redução no número de ligações intermoleculares entre polímeros amiláceos, explicando a redução da força ${ }^{[25]}$. Este efeito também foi reportado por Vicentini ${ }^{[33]}$.

Assim como observado no presente trabalho (Figura 4), outros autores também relataram redução na força de perfuração com o aumento da concentração de glicerol. Mali et al. ${ }^{[34]}$ observou em filmes de amido de cará que o aumento da concentração de glicerol de 1,3 para $2,0 \%$ causou a redução da força de perfuração de 8,02 para 6,03 $\mathrm{N}$. Vicentini ${ }^{[33]}$ verificou que o incremento de glicerol de $10 \%$ para $25 \%$ levou a uma redução da força de perfuração de 7,25 para 4,28 N. Este comportamento se deve ao rompimento de interações intermoleculares ocasionado pela presença do plastificante ${ }^{[35]}$.

Em relação ao efeito do $\mathrm{pH}$, a força de ruptura dos filmes primeiramente aumentou e depois declinou com o aumento do $\mathrm{pH}$ (Figura 4). Os maiores valores ocorreram em $\mathrm{pH}$ próximo à neutralidade. Segundo Cao et al. ${ }^{[22]}$, em

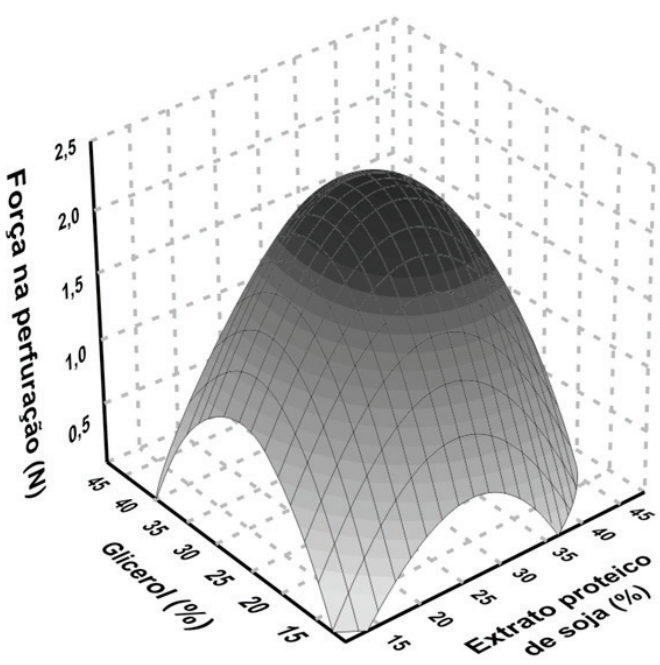

(a)

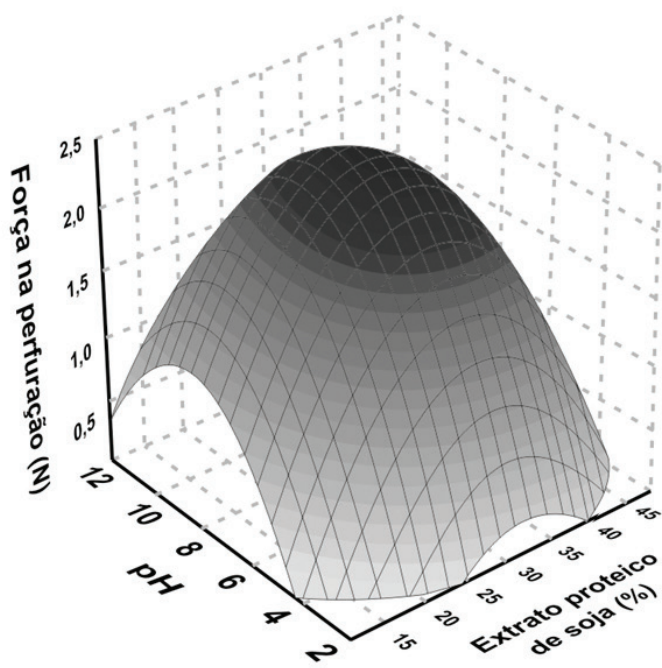

(b)

Figura 4. Efeito dos teores de glicerol, extrato proteico de soja e do $\mathrm{pH}$ na força de perfuração de filmes de amido de mandioca. (a) $\mathrm{pH}$ 7,0 e (b) glicerol $30 \%$.

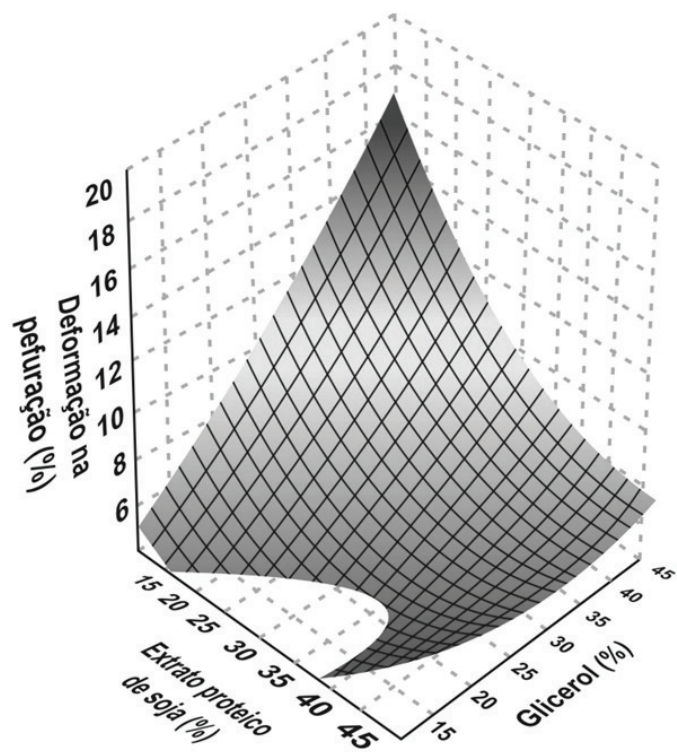

(a)

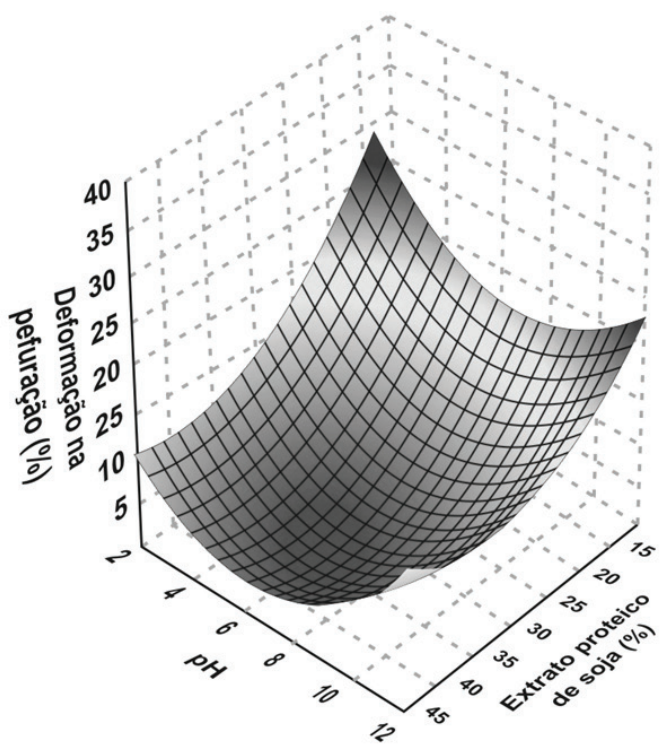

(b)

Figura 5. Efeito dos teores de extrato proteico de soja, glicerol e do pH na deformação na perfuração de filmes de amido de mandioca. (a) $\mathrm{pH} 7,0$ e (b) glicerol $30 \%$. 
Tabela 3. Condições de desejabilidade $\left(\mathrm{d}_{\mathrm{i}}\right)$ das variáveis respostas durante a otimização da produção dos filmes a base de amido de mandioca, extrato proteico de soja e glicerol, elaborados em diferentes $\mathrm{pHs}$.

\begin{tabular}{|c|c|c|c|c|c|c|c|}
\hline \multirow{2}{*}{$\begin{array}{l}\text { Variável } \\
\text { Resposta }\end{array}$} & & \multicolumn{3}{|c|}{ Condição I } & \multicolumn{3}{|c|}{ Condição II } \\
\hline & & Mínimo & Médio & Máximo & Mínimo & Médio & Máximo \\
\hline \multirow[t]{2}{*}{ Opacidade } & Valor & 2,16 & 3,52 & 4,88 & 2,16 & 3,52 & 4,88 \\
\hline & $\mathrm{d}_{\mathrm{i}}^{\mathrm{a}}$ & 1,00 & 0,50 & 0,00 & 1,00 & 0,50 & 0,00 \\
\hline \multirow[t]{2}{*}{ Cor } & Valor & 8,14 & 12,70 & 17,26 & 8,14 & 12,70 & 17,26 \\
\hline & $\mathrm{d}_{\mathrm{i}}$ & 1,00 & 0,50 & 0,00 & 1,00 & 0,50 & 0,00 \\
\hline \multirow[t]{2}{*}{ Solubilidade em água } & Valor & 14,74 & 37,90 & 60,96 & 14,74 & 37,9 & 60,96 \\
\hline & $\mathrm{d}_{\mathrm{i}}$ & 1,00 & 0,00 & 0,00 & 0,00 & 1,00 & 1,00 \\
\hline \multirow[t]{2}{*}{$\mathrm{PVA}^{\mathrm{b}}$} & Valor & 0,17 & 0,27 & 0,37 & 0,17 & 0,27 & 0,37 \\
\hline & $\mathrm{d}_{\mathrm{i}}$ & 1,00 & 0,00 & 0,00 & 1,00 & 1,00 & 0,00 \\
\hline \multirow[t]{2}{*}{ Força de perfuração } & Valor & 0,08 & 1,43 & 2,78 & 0,08 & 1,43 & 2,78 \\
\hline & $\mathrm{d}_{\mathrm{i}}$ & 0,00 & 0,50 & 1,00 & 0,00 & 0,50 & 1,00 \\
\hline \multirow[t]{2}{*}{ Deformação na perfuração } & Valor & 0,09 & 10,99 & 21,88 & 0,09 & 10,99 & 21,88 \\
\hline & $\mathrm{d}_{\mathrm{i}}$ & 0,00 & 0,50 & 1,00 & 0,00 & 0,50 & 1,00 \\
\hline
\end{tabular}

${ }^{\mathrm{a}}$ condições de desejabilidade; ${ }^{\mathrm{b}}$ permeabilidade ao vapor de água.

Tabela 4. Valores para a função desejabilidade (D) para a otimização da elaboração dos filmes a base de amido de mandioca, extrato proteico de soja e glicerol elaborados em diferentes $\mathrm{pHs}$.

\begin{tabular}{cccccccccc}
\hline Condição & D & EPS & GLI & pH & PVA & $\Delta \mathbf{E}$ & Sol & FP & DP \\
\hline I & 0,00 & 19,79 & 32,62 & 7,33 & 0,28 & 9,61 & 46,56 & 1,94 & 9,25 \\
II & 0,99 & 15,19 & 29,22 & 6,12 & 0,27 & 8,23 & 37,90 & 1,43 & 11,50 \\
\hline
\end{tabular}

$\mathrm{D}=$ Função desejabilidade; EPS = Extrato proteico de soja (\%); Gli = Glicerol (\%); PVA = Permeabilidade ao vapor de água; $\Delta \mathrm{E}=$ Diferença de cor; Sol = Solubilidade; FP = Força de perfuração; DP = Deformação na perfuração.

pH baixo (próximo ao pI da proteína) não há interação entre o amido e a proteína, resultando em redução da força. Já em $\mathrm{pH}$ alto, a redução da força pode ser explicada por uma possível hidrólise dos polímeros.

\section{Deformação na perfuração}

A deformação na perfuração foi influenciada por todos os fatores nos níveis linear e quadrático e pelas interações. Quanto menor o teor de EPS e maior o de glicerol, maior foi a deformação dos filmes (Figura 5), obtendo um máximo de $31,9 \%$ na condição de $13 \%$ de EPS e $47 \%$ de glicerol. A ação do plastificante aumentando a deformação já é bastante conhecida. Ele age entre as cadeias poliméricas reduzindo interações, aumentando a mobilidade e consequentemente, tornando os filmes mais extensíveis ${ }^{[36]}$.

O efeito da redução de proteína aumentando a deformação pode estar relacionado ao aumento do teor de amido do filme. A diminuição da deformação com o aumento da concentração de proteína também foi observado por Lee et al. ${ }^{[37]}$. Segundo os autores, a ocorrência de extensivas ligações intermoleculares inibindo a reorientação e o alinhamento da proteína e da cadeia de amido pode explicar este efeito.

$\mathrm{O}$ pH também afetou a deformação dos filmes, sendo que nos extremos ( $\mathrm{pH} 2,0$ e $\mathrm{pH} 12,0)$ os materiais apresentaram maior deformação (entre 19 e $22 \%$ ) quando o teor de EPS foi $15 \%$ e o glicerol foi $30 \%$. A menor deformação (1,4\%) ocorreu na condição de $37 \%$ de EPS, $30 \%$ de glicerol em pH neutro. Este efeito pode ser explicado pelo pI da proteína. As condições ácidas ( $\mathrm{pH} 1,0$ a 3,0) e as condições alcalinas $(\mathrm{pH} 8$ a 14) avaliadas neste estudo estavam distantes do pI da proteína de soja ( $\mathrm{pH} 4,5)$. Nestas condições, as interações proteína-proteína são menores, o que já reflete positivamente no aumento da deformação. No entanto, este efeito também ocasiona maior facilidade de interação entre os polímeros e o glicerol. Assim, com a redução das interações poliméricas, ocorre o aumento da mobilidade molecular e a elevação da deformação ${ }^{[38]}$.

\section{Otimização da produção dos filmes de amido de mandioca}

Para a otimização do processo de produção dos filmes foi considerado seu uso como embalagem protetora contra alterações provocadas por umidade, luz, ataque microbiano e insetos. Para isto os filmes devem possuir baixa PVA, baixa solubilidade e propriedades mecânicas que permitam a manutenção da integridade do filme durante a manipulação, empacotamento e transporte, aliadas a uma boa transparência. Assim, foram adotados critérios com base nas restrições citadas para os valores mínimos, intermediários e máximos de cada resposta (condição I da Tabela 3) para encontrar os valores operacionais ótimos das variáveis independentes que satisfaçam simultaneamente os requisitos necessários às variáveis respostas (função desejabilidade), com valores baixos de permeabilidade e solubilidade. Contrariamente, também foram adotados critérios que foram estabelecidos na condição II com valores intermediário e alto para solubilidade e intermediário e baixo para permeabilidade, mantendo os valores $d_{i}$ constantes para as demais respostas. Com base nos resultados da função desejabilidade (Tabela 4) foi possível verificar que para se obter o máximo valor desta função global, ou seja igual a 1,0, ter-se-á que operar os fatores EPS, GLI e pH, em 15,19\%, 29,22\% e 6,12 , respectivamente. O filme assim elaborado possuirá 
valores intermediários de PVA $\left(0,27 \mathrm{~g} \mathrm{~mm} \mathrm{~h}^{-1} \mathrm{~m}^{-2} \mathrm{kPa}^{-1}\right) \mathrm{e}$ solubilidade $(37,90 \%)$, podendo ser uma alternativa para a aplicação em produtos que necessitem de hidratação prévia ao consumo, ou mesmo, em cobertura de sementes agrícolas que necessitem de rápida absorção de água para germinarem no campo ou como carreadores de aditivos necessários ao crescimento das mesmas.

\section{Conclusão}

Foi possível elaborar filmes com misturas de amido de mandioca e extrato proteico de soja variando-se o $\mathrm{pH}$ e o teor de glicerol. A adição de extrato proteico de soja resultou em um aumento da solubilidade, da diferença de cor (amarelecimento) e na redução da deformação na ruptura. A combinação de baixos teores de proteína e de glicerol em $\mathrm{pH}$ alcalino reduziu a permeabilidade ao vapor de água. Como resultado da otimização, considerando-se os fatores desejáveis: baixa permeabilidade ao vapor de água, baixa solubilidade e boa resistência mecânica, as melhores condições de processo que atenderiam a estas características foram $15,2 \%$ de extrato proteico de soja, $29,2 \%$ de glicerol em $\mathrm{pH} 6,1$.

\section{Agradecimentos}

Ao CNPq, Embrapa e FAPERJ (Processo n. E-26/111.483/2008).

\section{Referências Bibliográficas}

1. Aider, M. - Food Sci. Technol., 43, p.837 (2010).

2. Rosa, D. S.; Chui, Q. S. H.; Pantano Filho, R. \& Agnelli, J. A. M. - Polímeros, 12, p.311 (2002).

3. Rosa, D. S.; Franco, B. L. M. \& Calil, M. R. - Polímeros, 11, p.82 (2001). http://dx.doi.org/10.1590/S010414282001000200010 .

4. Mali, S.; Grossmann, M. V. E. \& Yamashita, F. - Semina, 31, p.137 (2010).

5. Avérous, L. \& Halley, P. J. - Biofuels, Bioproducts and Biorefining, 3, p.329 (2009). http://dx.doi.org/10.1002/ bbb. 135 .

6. Pommet, M.; Redl, A.; Morel, M.-H. \& Guilbert, S. Polymer, 44, p.115 (2003). http://dx.doi.org/10.1016/S00323861(02)00746-2.

7. Mauri, A. N. \& Añón, M. - J. Sci. Food Agric., 86, p.1064 (2006). http://dx.doi.org/10.1002/jsfa.2457.

8. Carvalho, R. A. \& Grosso, C. R. F. - Ciênc. Tecnol. Aliment., 26, p.495 (2006). http://dx.doi.org/10.1590/S010120612006000300002.

9. Tang, R.; Du, Y.; Zheng, H. \& Fan, L. - J. App. Polym. Sci., 88, p.1095 (2003). http://dx.doi.org/10.1002/app.11703.

10. Companhia Nacional de Abastecimento - Conab. - "Panorama Internacional e Nacional da Mandiocultura". Ministério da Agricultura, Pecuária e Abastecimento, Brasília . Disponível em: $<$ http://www.agricultura.gov.br/arq $>$.

11. Monterrey-Quintero, E. S. \& Sobral, P. J. A. - Pesquisa Agropecu. Bras., 35, p. 179 (2000). http://dx.doi.org/10.1590/ S0100-204X2000000100020.

12. Zhang, J.; Mungara, P. \& Jane, J. - Polymer., 42, p.2569 (2001). http://dx.doi.org/10.1016/S0032-3861(00)00624-8.
13. Coupland, J. N.; Shaw, N. B.; Monahan, F. J.; Dolores O'Riordan, E. \& O'Sullivan, M. - J. Food Eng., 43, p.25 (2000). http://dx.doi.org/10.1016/S0260-8774(99)00129-6.

14. Madaleno, E.; Rosa, D. S.; Zawadzki, S. F.; Pedrozo, T. H. \& Ramos, L. P. - Polímeros, 19, p.263 (2009). http://dx.doi. org/10.1590/S0104-14282009000400004.

15. Gennadios, A.; Weller, C. L.; Hanna, M. A. \& Froning, G. W. - J. Food Sci., 61, p.585 (1996). http://dx.doi. org/10.1111/j.1365-2621.1996.tb13164.x.

16. Shiku, Y.; Yuca Hamaguchi, P.; Benjakul, S.; Visessanguan, W. \& Tanaka, M. - Food Chem., 86, p.493 (2004). http://dx.doi. org/10.1016/j.foodchem.2003.09.022.

17. Gontard, N.; Guilbert, S. \& Cuq, J. L. - J. Food Sci., 57, p.190 (1992). http://dx.doi.org/10.1111/j.1365-2621.1992. tb05453.x.

18. American Society for Testing and Materials - ASTM - "ASTM D 882-00: Standard test methods for tensile properties of thin plastics sheeting", ASTM, Philadelphia (2001).

19. Gontard, N. - "Films et enrobages comestibles: étude amélioration dês propriétés filmogènes du glúten", Tese de Doutorado, Université des Sciecens et techniques du Languedoc, Montpellier (1991).

20. Box, G. E. P.; Hunter, W. G. \& Hunter, J. S. - "Statistics for experimenters: introduction to design, data analysis and model building", John Wiley \& Sons, New York (1978).

21. Thompson, D. R. - J. Food Proc Preserv., 6, p.155 (1982). http://dx.doi.org/10.1111/j.1745-4549.1982.tb00650.x.

22. Cao, N.; Fu, Y. \& He, J. - J. Food Hydrocoll., 21, p.1153 (2007). http://dx.doi.org/10.1016/j.foodhyd.2006.09.001.

23. Sobral, P. J. A.; García, F. T.; Habitante, A. M. Q. B. \& Monterrey-Quintero, E. S. - Pesq. Agropec. Bras., 39, p.255 (2004). http://dx.doi.org/10.1590/S0100204X2004000300008

24. Sobral, P. J. A. - Pesq. Agropec. Bras., 35, p.1251 (2000). http://dx.doi.org/10.1590/S0100-204X2000000600022.

25. Fakhoury, F. M.; Martelli, S. M.; Bertan, L. C.; Yamashita, F.; Innocentini-Mei, L. H. \& Queiroz, F. P. C. - Food Sci. Technol., 49, p.149 (2012).

26. Rhim, J. W. \& Lee, J. H. - Food Sci. Biotechnol., 13, p.728 (2004).

27. Jamilah, B.; Mohamed, A.; Abbas, K. A.; Rahman, R. A.; Karim, R. \& Hashim, D. M. - J. Food Agric. Environ., 7, p.169 (2009).

28. Bourtoom, T.; Chinnan, M. S.; Jantawat, P. \& Sanguandeekul, R. - Lebenson Wiss Technol., 39, p.405 (2006).

29. Jiang, J.; Xiong, Y. L.; Newman, M. C. \& Rentfrow, G. K. Food Chem., 132, p.1944 (2012). http://dx.doi.org/10.1016/j. foodchem.2011.12.030.

30. Cuq, B.; Gontard, N.; Cuq, J. L. \& Guilbert, S. - J. Agric. Food Chem., 45, p.622 (1997). http://dx.doi.org/10.1021/jf960352i.

31. Bemiller, J. N. \& Whistler, R. L. - “Carbohydrates”, in: Food Chemistry, 3rd ed., Owen R. Fennema (ed.), Marcel Dekker, New York, p.157 (1996).

32. Swain, S. N.; Biswal, S. M. \& Nayak, P. L. - J. Polym. Environ., 12 (2004).

33. Vicentini, N. M. -"Elaboração e caracterização de filmes comestíveis a base de fécula de mandioca para uso em póscolheita ", Tese de Doutorado, Universidade Estadual Paulista, Brasil (2003). 
34. Mali, S.; Grossmann, M. V. E.; García, M. A.; Martino, M. N. \& Zaritzky, N. E. - Carbohydr. Polym., 56, p.129 (2004). http://dx.doi.org/10.1016/j.carbpol.2004.01.004.

35. Mangavel, C.; Barbot, J.; Guéguen, J. \& Popineau, Y. - J. Agric. Food Chem., 51, p.1447 (2003). http://dx.doi. org $/ 10.1021 / \mathrm{jf0} 257704$.

36. Galdeano, M. C.; Mali, S.; Grossmann, M. V. E.; Yamashita, F. \& Garcia, M. A. - Mater. Sci. Eng. C., 29, p.532 (2009). http://dx.doi.org/10.1016/j.msec.2008.09.034.
37. Lee, K. Y.; Shim, J. \& Lee, H. G. - Carbohydr. Polym., 56, p.251 (2004). http://dx.doi.org/10.1016/j.carbpol.2003.04.001.

38. Monterrey, E. S. \& Sobral, P. J. A. - Ciênc. Tecnol. Aliment., 19 (1999).
Enviado: Fev. 01, 2013

Reenviado: Mar: 11, 2014

Aceito: Abr. 24, 2014 